\title{
Identity play and the stories we live by
}

\author{
Babak Ghaempanah \\ School of Business and Economics, Vrije Universiteit Amsterdam, Amsterdam, \\ Netherlands, and \\ Svetlana N. Khapova \\ School of Management and Organization, Vrije Universiteit Amsterdam, \\ Amsterdam, Netherlands
}

\begin{abstract}
Purpose - The purpose of this paper is to advance our understanding of identity play process by including the stories we live by in depth. Over the past decade, identity play literature has placed more emphasis on the role of self-narratives. Yet, the "stories we live by", including the told or untold stories of past and imagined events of the future, have not been considered in depth in these self-narratives.

Design/methodology/approach - This conceptual paper draws on the personal construct theory, narrative identity and constructivist psychotherapy literatures and attempts to include the stories we live by in scholarly conceptualizations and explorations of identity play processes.

Findings - Drawing on the personal construct theory, narrative identity and constructivist psychotherapy literatures this paper offers a comprehensive conceptual model of how the stories we live by infuse individual identity construction processes. The model highlights the inter-connectivity among stories we live by, identity play, identity work, sensemaking and social validation. Looking through the lens of the personal construct theory and taking these inter-connectivities into account lead to the observation of temporality in identity construction and the plurivocality of self-narratives.

Originality/value - This paper looks at identity play through the lens of the personal construct theory. However, self-narratives are seen as a medium for manifestation of personal constructs. Thus, this paper also draws on the narrative identity literature and dialogical-self concept, which helps access the multiplicity of the self-narratives to widen our grasp of personal constructs. This paper combines discourse of deconstruction with the dialogical-self concept and provides more means for the explication of identity play.
\end{abstract}

Keywords Identity play, Personal construct theory, Identity work, Narrative, Stories we live by, Constructivism, Temporality, Plurivocality

Paper type Conceptual paper

If you want to know me, then you must know my story, for my story defines who I am. And if I want to know myself, to gain insight into the meaning of my own life, then I, too, must come to know my own story. I must come to see in all its particulars the narrative of the self- the personal myth- that I have tacitly, even unconsciously, composed over the course of my years. It is a story I continue to revise, and tell to myself (and sometimes to others) as I go on living.

Dan P. McAdams, The Stories We Live by

\section{Introduction}

Identity play is a recent and less investigated area of research. The focus on identity play has emerged from observing the gap in the extant identity work literature with regard to

(C) Babak Ghaempanah and Svetlana N. Khapova. Published by Emerald Publishing Limited. This article is published under the Creative Commons Attribution (CC BY 4.0) licence. Anyone may reproduce, distribute, translate and create derivative works of this article (for both commercial \& noncommercial purposes), subject to full attribution to the original publication and authors. The full terms of this licence may be seen at: http://creativecommons.org/licences/by/4.0/legalcode 
JOCM 33,5

\section{4}

explaining the phenomenon whereby individuals engage in experimenting with and crafting possible selves (Ibarra and Petriglieri, 2010). Within this area of research, the role of narratives in identity construction has received more attention over the past ten years (Ashforth et al., 2008; Ibarra and Barbulescu, 2010; Slay and Smith, 2011; Brown, 2015). Individuals' self-narratives have been found to be a crucial element in the process of identity work or play (Ibarra and Petriglieri, 2010; Brown, 2015). Consequently, relevant literature reviews have been calling for more research on self-narratives of individuals, i.e. the narratives that individuals tell about their work, selves and past to others and themselves (Brown et al. 2008; Ibarra and Barbulescu, 2010; Ashforth et al., 2008; Caza et al., 2018). However, the extant literature on identity play has yet made little effort to integrate, in depth, the stories we live by in our self-narratives. Hence, we still know little about the dynamics of the narratives and how the stories we live by shape identity play. "Stories we live by" refers to the told or untold stories of the past and the imagined events of the future (McAdams, 1993).

The subject of identity is linked to almost every topic of organization studies, for example, organizational change (Brown, 2015; Alvesson et al., 2008), which affects the development of individuals' identities and triggers engagement in identity construction processes (Reissner, 2010; Conroy and O'Leary-Kelly, 2014; Brown et al., 2009). Hence, a deeper understanding of identity play as a mode of engagement in identity construction is critical. Additionally, in the domain of identity play, it is urgent and relevant to attend to the stories we live by, as a new generation of narrative identity researchers have agreed that narratives are central to the formation of identity (Singer, 2004). Narratives of past and potential future form the current self-meaning, and the extant literature has not sufficiently integrated the temporal element of stories (Caza et al., 2018). The term narrative identity has been developed based on the human ability to store and retrieve experiences in the form of autobiographical memories and generate meaning and continuity by integrating those memories (Hallford and Mellor, 2017). Narratives also play a crucial role in "sensemaking," "sensegiving" and "sense-breaking" (Ashforth et al., 2008), which are critical in understanding work-related identity (Koerner, 2014; Reissner, 2010).

Overlooking the stories we live by in the extant identity play literature is problematic because, first, excluding these stories may lead to theories that provide limited understanding and predictive ability. Second, without including the stories we live by, the dynamics between identity play and identity work become ambiguous, while the stories provide a continuum between consistency and change (Ashforth et al., 2008); hence, identity work and play will not necessarily appear as a dichotomy, as argued by some scholars in the extant literature (Fachin and Davel, 2015). Third, this paper argues that if the stories we live by are not included in depth, temporality and multiplicity (including even fragmentations as opposed to coherence), which are more recent areas of concern in the literature of identity play and work (Ericson and Kjellander, 2018; Brown et al., 2009) will not be observed. Most organizational research on identity has looked at identities in isolation in a specific context and neglected the multiplicity of an individual's identities (Caza et al., 2018).

The purpose of this paper is to advance our understanding of the identity play process by including the stories we live by in depth. However, identity work is also discussed because of its interconnectivity with identity play, which is deduced from the scholarly debates in the extant literature (Fachin and Davel, 2015; Ibarra and Petriglieri, 2010; Ashforth et al., 2008; Caza et al., 2018). This paper looks at identity play through the lens of the personal construct theory (Chiari and Nuzzo, 2010). However, self-narratives are seen as a medium for manifestation of personal constructs (Raskin, 2010). Thus, this paper also draws on narrative identity and narrative therapy literatures and later refers to the dialogical-self concept, which helps access the multiplicity of the self-narratives to widen our grasp of personal constructs.

Consequently, this paper argues that for a deeper understanding of identity play, interconnectivities among stories we live by, identity construction and sensemaking shall be 
acknowledged. By doing so, temporality in identity and plurivocality in the stories we live by are brought into the picture.

Some may argue that the root cause of engagement in identity play should be investigated through unconscious psychodynamics; however, this paper suggests staying with the narrative, but going deeper. This recommendation stems out of a desire to remain consistent with the epistemology of constructivism. It is also based on agreement with some authors who have argued "that while modernity privileged the voice of scientific authority over the voice of experience, a feature of our times is the resurgence of the voice of experience" (Brown et al., 2009, p. 330).

This paper continues with a review of the existing scholarship in the field of identity work and play literature; next, the argument is located within an identified and important literature gap; and finally, the paper proposes a conceptual model and a theoretical foundation with which to address the identified gap. Finally, themes and areas for future research are proposed.

\section{Identity work and play literature thus far}

Scholars note that the subjects of identity and identity work are linked to every topic in organization studies (Brown, 2015; Alvesson et al., 2008). Identity can be defined as a selfreferential description that provides contextually appropriate answers to the question "Who am I?" or "Who are we?" (Ashforth et al., 2008); these questions are often viewed in personal or social terms.

There are three dominant literature streams in identity work: one is associated with social cognition, one with post-structuralism and power and one with psychodynamics (Brown, 2015). The first stream focuses on inter-group and social interactions in identity work processes. The second focuses on the discourses of the context, which can shape and influence individual identities, and one of its main areas of concern is identity control or regulation and the management of the inside (Beech, 2008; Alvesson and Willmott, 2002). The last stream, to which this study belongs, focuses on identity work or play at the individual level. Both psychodynamic and narrative or storytelling approaches are common among scholars in this stream. The three streams look at identity work from different angles and at different levels. A recent and comprehensive review of identity work literature by Caza et al. (2018) has categorized the dominant theoretical lenses that researchers have used in each stream. The narrative and identity theories have commonly been used at an individual level, while the social and critical identity theories at group and organizational context levels (Caza et al., 2018). However, it is important to mention that all three literate streams in identity work share an interest in identity narratives (Brown, 2015; Caza et al., 2018). This interest stems from the characteristics of the narratives, which are considered socially negotiated (suitable for the social cognition research stream), spatially and temporally contextualized and linguistically formed (suitable for the post-structuralist research stream) and psychologically channelized (suitable for the psychodynamic research stream). However, narrative studies in the social cognition and post-structuralist streams of research focus on narratives at the group and organization level or at the context level. The studies by Rosile et al. (2013) on storytelling organization are a good example of research in the post-structuralist stream with a focus on narratives. The psychodynamic approach also often recognizes the self-narrative as a source of knowledge to explicate the identity work dynamic. This is, for example, clear in studies by Shepherd and Williams (2018) on studying hitting rock bottom from a cognitive perspective or Petriglieri and Stein's (2012) study on projective identification from a psychodynamic perspective.

According to the identity work literature, in response to identity tensions, individuals engage in the process of "forming, repairing, maintaining, strengthening or revising"

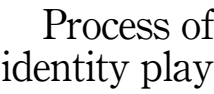

685 
JOCM 33,5

686
(Sveningsson and Alvesson, 2003, p. 1165) their identities to achieve a sense of coherence and distinctiveness (Sveningsson and Alvesson, 2003; Pratt et al., 2006). Scholars note that people also engage in identity work to achieve a sense of authenticity (Watson, 2008; Tracy and Trethewey, 2005). Scholars have studied identity work engagement in response to various identity tensions, for instance, career loss (Fraher and Gabriel, 2014), role change (Ibarra and Barbulescu, 2010), integrity violation (Pratt et al., 2006), acts of courage (Koerner, 2014), workrelated identity loss (Conroy and O'Leary-Kelly, 2014) or with regard to stigmatized cultural identities (Slay and Smith, 2011). Identity tension can be seen as a threat, an opportunity or as equivocal (ambiguous) (Ashforth et al., 2016).

In a lesser-known phenomenon, the individual may also engage in the process of identity play, which entails "crafting and provisional trial of immature (i.e. as yet unelaborated) possible selves" (Ibarra 2010). This is a more recent area of research, and scholars are studying what drives people to engage in it. For example, a study by Ashforth et al. (2016) focused on the nature of tension from a Freudian perspective, proposing that an identity tension that is perceived as a threat leads to identity work and, once perceived as opportunity, leads to identity play. A study by Shepherd and Williams (2018), using a cognitive approach, aims to answer why when facing a strong tension that shatters an existing identity, some people engage in creating possible new selves, whereas other people get stuck. Last but not least, the study by Costas and Grey (2014) looks into the imagination of future selves, regardless of their actualization in reality, as a postalgic response to disciplinary power.

The extant literature on identity play brings some critical areas of debate to our attention. First, there is the assumption of a safe environment for identity play. The study by Ibarra and Petriglieri (2010) describes identity play as testing or experimenting with a possible self and assume a safe environment as a prerequisite for such experimentation. However, some studies consider identity play as not merely experimenting but rather creating, and furthermore, they do not assume a safe environment (Fraher and Gabriel, 2014). The second area of debate is whether the relation between identity work and play should be viewed as a dichotomy or a spectrum (Fachin and Davel, 2015). Furthermore, a review of current scholarship on identity work and play highlights the need for process-focused studies with a theoretical basis as well as studies on temporality for identity work or play (Ericson and Kjellander, 2018; Ainsworth and Grant, 2012; Ibarra and Barbulescu, 2010). Additionally, the contemporary views of narrative identity invite us to attend not only to temporality but also to multiplicity (or the plurivocality of stories) as current areas of concern (Hermans, 2001; Brown et al., 2009; Fraher and Gabriel, 2014; Ericson and Kjellander, 2018). While coherence and integration have been emphasized in the extant literature on identity work (Ibarra and Barbulescu, 2010), the contemporary view on narrative identity has brought the plurivocality of self-narratives, or the dialogical self, as theorized by Herman, into the picture (Hermans, 2001). Although integration and coherence seem necessary for functioning, it can be misleading to assume an integrated and coherent underlying self (Raggatt, 2006). The concept of the dialogical self (Hermans, 2001) sheds light on multiplicity, conflict and even contradiction in narratives.

\section{Why consider stories we live by in identity work/play literature?}

The idea that an individual creates identity through stories has developed over the past two decades (McAdams and McLean, 2013). Through narrative processing, stories are constructed to organize life experiences and past events in the form of anecdotes or autobiographies, and narrative memory becomes the building block of identity (Singer and Bluck, 2001). For this reason, "narrative identity researchers take seriously McAdams's proposal that "identity is a life story"' (Singer, 2004).

The self-narratives of individuals, told or untold, are sources of meaning that are developed through lived experiences and are fundamental in all areas of life (McLean et al., 
2007). Looking at self-narrative at the situational level, although might offer some insight, cannot reveal the dynamics that the individual is going through during the identity play process. The question of what stories are dominant in identity play cannot be answered by the extant literature. Answering this question can lead us to new insights by highlighting narrative patterns, themes and their evolution, deconstruction or fixation throughout time.

According to Singer, "To understand the identity formation process is to understand how individuals craft narratives from experiences, tell these stories internally and to others, and ultimately apply these stories to knowledge of self, other and the world in general" (Singer, 2004). On the other hand, constructivist psychotherapy with a narrative approach aims to support the well-being of the individuals through the process of de- and re-construction of those stories (White and Epston, 1990). Narration brings the narrator into awareness of his or her dominant or even competing interpretations and his or her preferences among them (Polletta and Lee, 2006; Weick, 1995). This understanding is consistent with George Kelly's personal construct theory and the concept of the "construction system." People de- and reconstruct their narratives by selecting a more meaningful version of the plot of their experience while acting out their stories (Chiari and Nuzzo, 2010). The de- and re-construction of narratives help author the unwritten versions of stories to facilitate alternative anticipations of the events (White and Epston, 1990; Mahoney, 2005). Regardless of coaching or therapy, individuals are constantly, knowingly or unknowingly, participating in re-writing their narratives through different phases of life to maintain a coherent narrative (Singer, 2004). The outcome of the identity play process, experimenting with possible selves, is similar to that of narrative therapy, which is authoring new stories through the process of deconstructing the old stories. This similarity invites us to attend to the discourse of deconstruction in the making of the identity play process.

The narration that narrative therapy is interested in is one with "thick" descriptions. The stories we live by are interwoven with the stories of other people and events; thick description includes individual interpretations of those others or events in the story and is inscribed with the meanings of the community of persons to which the narration is relevant (White, 1997).

Recent research from cognitive and neurological perspectives has shed more light on the role of narratives in identity construction (Conway and Pleydell-Pearce, 2000; Conway et al., 2004; Demblon and D'Argembeau, 2017). Autobiographical memory is seen to be "of fundamental significance for the self, for emotions, and for the experience of personhood, that is, for the experience of enduring as an individual, in a culture, over time" (Conway and Pleydell-Pearce, 2000). Autobiographical knowledge is encoded through the goal structure of the working self, which also plays a major role in the construction of specific memories during remembering (Conway and Pleydell-Pearce, 2000). Hence, personal identity is not only fed by the memories of the past or the imagined event of the future, but also depends on the formation of a coherent network of related events (Demblon and D'Argembeau, 2017). More specifically, the network of events where self-defining memories of past or imagined future events with similar identity motives are linked is thought to bring about the construction of identity (Demblon and D'Argembeau, 2017). Furthermore, the study clarified that the nature of the connections linking events within these networks has a narrative-like structure (Demblon and D'Argembeau, 2017). According to Conway and Pleydell-Pearce (2000), the ability to create a life-story narrative emerges in late adolescence (Conway and Pleydell-Pearce, 2000). Habermas and Bluck (2000) argued that this is because of the development of a life-story schema at this age (Habermas and Bluck, 2000). A life-story schema is conceptualized as a latent knowledge structure that facilitates the generation of life narratives (Singer, 2004).

Combining the conclusions of these studies provides more insight into the nature of the stories we live by. These stories are not merely chronicles, but also a self-defining network of events that are structured narratively with coherence and include the motives of the identity

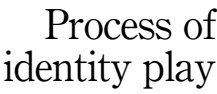

687 
JOCM 33,5

\section{8}

and the goals of the self-schema. Consequently, drawing on stories, shifting the dominance from one story to another, modifying the significance of stories, de- or re-constructing stories become the underlying tasks that individuals engage in constructing their identities. This can be an intense engagement in response to an immediate tension or an ongoing evolvement through life experiences. Looking through this angle, we agree with Caza et al.'s (2018) suggestion that identity work should be replaced by self-work, and additionally, we suggest this also includes identity play.

\section{Stories we live by in identity work/play: a conceptual model}

Based on the theoretical foundation and literature review presented earlier in this paper, a conceptual process model is proposed wherein identity tension, work, play, sensemaking, social feedback and the stories we live by are interlinked. Our conceptual model, Figure 1, provides a holistic process view for identity play and work and brings temporality into light. The sections below elaborate on the elements of the proposed conceptual model. The personal construct theory, which views personal constructs as the drivers behind someone's cognition and behaviors, remains fundamental in the proposed model. However, personal constructs are too abstract to access; thus, narrative and constructivist psychotherapy literatures, as well as the dialogical-self concept, act as tools for accessing personal constructs through stories we live by. Delving into the world of stories that we live by is an inward journey and a search for local knowledge [1].

\section{Identity tension and identity work or play}

Identity tension, shown in the arrow in the left side of Figure 1, can be perceived as a threat, opportunity or have equivocal or ambiguous nature. The model shows that tension leads into identity work or play. This part of the proposed model is based on the extant literature on identity work and play, for example (Ibarra and Petriglieri, 2010; Pratt et al., 2006; Ibarra and Barbulescu, 2010), and cites engagement in identity work or play as a response to identify tension with the aim of regaining coherence, distinctiveness or creation of possible selves. However, based on the narrative identity literature discussed in the previous section; this engagement in identity work or play involves narrativization, meaning translation of experience into narrative for meaning-making (McAdams and McLean, 2013; Singer, 2004).

Figure 1.

Holistic conceptual model for identity play and work

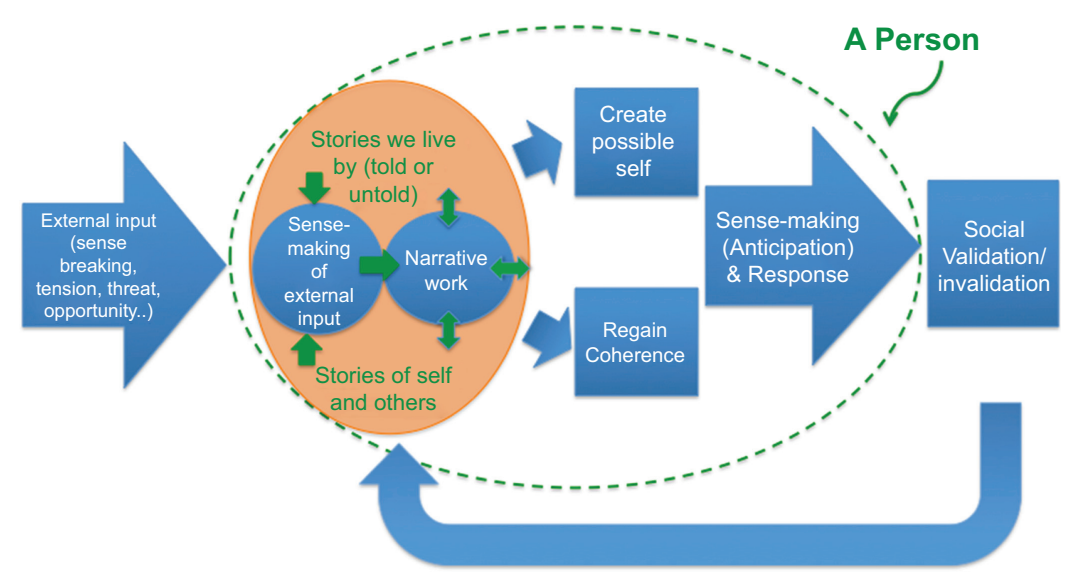


Therefore, as shown in the model, the link between identity tension and identity work or play passes through sensemaking of the tension and narrative work.

P1. The tension triggers sensemaking of the tension (opportunity, threat, equivocal), which is followed by narrativization and leads to identity work or play aiming for coherence, distinctiveness or creation of a new possible self.
Process of identity play

\section{Stories we live by, sensemaking of tension and narrativization}

This section refers to the ellipse shown in Figure 1, which embraces the stories we live by, and is the core focus of this paper and the heart of this conceptual model. The point here is that the sensemaking of the tension and the narrativization that takes place in engagement in identity work or play are contextualized with the stories we live by. In other words, individuals engage in identity work or play with the pre-existing told or untold stories that they live by. The stories we live by, which form the narrative background of the individual, will impact his/her experience of the tension and his/her narrativization for the purpose of identity construction (McLean et al., 2007). While narrativization is working with the situational story, stories we live by provide the local knowledge that this narrativization draws upon. Stories we live by contextualize not only the narrativization but also the sensemaking of the tension. Consequently, the tension might be construed as a threat, opportunity or ambiguity through the lens of these stories. The theory behind this part of the process is based on the personal construct theory, narrative identity literature as well as the concept of the dialogical-self (Hermans, 2001).

Additionally, the stories we live by serve not only as a source for interpretation (meaning and sensemaking) but also as a medium through which emotions can arise. Emotion, in return, functions as a simulant for triggering identity construction and impact the reformation of identity (Winkler, 2018). Emotions stimulate a rationalization process to construct identities for the self and others (Cascon-Pereira and Hallier, 2012).

P2. Stories we live by contextualize the narrativization of the situational story and the interpretation of the identity tension, conceiving it as an opportunity, threat or ambiguity.

\section{Identity play or work?}

Moving forward with the proposed model in Figure 1, a question that can be raised is whether in facing an identity tension an individual engages in identity work or identity play. The extant literature on identity work and play is not rich enough to clarify the dynamics and processes leading to shift between identity work and play (Fachin and Davel, 2015). According to Ibarra and Petriglieri (2010), "by focusing our attention on how we work identities, we neglect the playful processes necessary for creating new possibilities". They argue, "our limited understanding of the processes by which identities evolve and change is partially due to the way, we have defined and investigated identity processes." The proposed model here also provides two paths, one toward creation of a possible self (play) and one toward regaining coherence (work). However, a crucial element in the model is that both paths are rooted in the stories we live by. Ashforth et al. (2016) propose that depending on the form of the identity tension, whether it is perceived as a threat or opportunity, the identity process, respectively, may follow identity work or play path. However, this model does not take an absolute position between the nature of the identity tension and the paths toward identity work or play; instead, proposes that depending on the dynamics among tension, narrativization, stories we live by and social validation feedback, the process might lead to identity work or play. The last proposition elaborates further on this, after all elements are discussed. 
JOCM 33,5

P3. Depending on the dynamic among identity tension, narrativization, stories we live by and social validation feedback, the identity process may take the path toward identity work or identity play.

\section{Identity and sensemaking}

Furthermore, from the sensemaking literature, it is deduced that an individual's identity acts as a source for sensemaking to draw from. Sensemaking is fundamentally linked to the identity construction processes of an individual, even though it is a social process (Brown et al., 2008). According to some scholars, narratives form the "primary cognitive tool" for sensemaking (Mink, 1978), and individuals make sense of "ambiguous stimuli" according to their own "identity needs" (Coopey et al., 1997). A study by Brown et al. (2008), which follows these scholars' views, sees sensemaking a narrative process and concludes that "sensemaking occurs in the context of individuals' idiosyncratic efforts at identity construction," and on that basis, they emphasize the necessity to attend to individuals' narratives (Brown et al., 2008). Following this argument, the proposed conceptual model has brought this interconnectivity between sensemaking and identity construction into the picture.

P4. Sensemaking and identity construction are interlinked. Individuals draw on their self-narratives for sensemaking and anticipation.

\section{Validation feedback on identity work/play}

Following Kelly's personal construct theory, an individual draws on his/her personal constructs to anticipate the future. The anticipation is then tested in real life and can be validated or invalidated. The response is then fed back to revise the personal constructs (Chiari and Nuzzo, 2010). In this sense, the process of developing a narrative identity is ongoing and is constantly being developed throughout life (Singer, 2004). The validation link also brings the socially negotiated nature of identity construction into the picture. Identity construction processes are not only often emotionally charged but also generally social (Brown, 2015). Hence, in addition to emotions that are discussed earlier, the dialogical input is another element to be considered simultaneously.

The identity work or play is not merely influenced by an individual's past and present stories and context or by the presence of an immediate threat; the outcome of the identity work or play, which leads to a source for sensemaking and anticipation, will be tested in a social context, the outcome of which will feed back to the identity work and play processes through the stories we live by.

P5. Sensemaking and anticipation are tested in reality and in a social context, which can be validated or invalidated. This social validation check is fed back to the selfnarrative or stories we live by.

\section{Stories we live by, temporality and multiplicity}

Following this proposed process, identity work or play takes as input not only the identity tension and the situational narrativization that follows it, but also the stories we live by and the response from social validation. A key element in this proposed conceptual model is the two-way communication between stories we live by and narrativization. While the individual is drawing on the stories he/she lives by, he/she may also engage in de- and re-constructions of the stories. This two-way influence indicates the elements of fixation and fluidity, meaning how much stories from the past influence the present (fixation) and how much does the present experience revise the past (fluidity). Dialogues that form among the four elements of 
tension, social feedback, narrativization and stories we live by, in time and space may reach a quasi-equilibrium state, lead to identity work or play.

A possibility that can arise from the dialogue among these four elements is deconstruction of the existing stories and reconstruction of new ones, bringing a temporal shift into the stories we live by. Following the philosophy behind the narrative therapy, this can lead into creating new possible self. The study by Fraher and Gabriel (2014) is a good example of the illustration of this proposition, wherein facing identity tension (layoff), some pilots were able to move on to new opportunities, while others remained stuck in their constructed identities. In other words, some experienced the temporality of their identity, deconstructed the old stories and reconstructed new stories, but for others, the stories of the past overpowered the temporality.

Furthermore, the dialogical-self concept brings the plurivocality of the stories we live by into our attention, which are linked to the multiplicity of the I-positions of an individual (Hermans 2001,2018). Taking the dialogical-self concept into account, another possibility that can arise from the dialogue among the four elements (tension, narrativization, stories we live by and social validation feedback) is a shift in the I-position, which is a spatial shift in the existing complex of stories.

P6. Identity play de- and re-constructs the stories of the past (temporal shift) or shifts the I-position in the dialogical self (spatial shift), allowing the occurrence of new interpretations and the creation of a new possible self.

In summary, stories we live by are not necessarily a stagnant or completely coherent body of information, but rather a dynamic and plurivocal complex, which is exposed to every moment of becoming. What also becomes observable in this model is the ongoing evolvement of identity even in the absence of tension; however, the evolvement is heightened in facing the tension (Caza et al.,2018). Additionally, in this evolvement, the individuals are active agents, who interpret and narrativize the streams of information from tension, stories they live by and social feedback.

\section{Discussion}

Acknowledging the recent scholarly view on attending to individuals' narratives in identity work and play studies, this paper goes one step further and emphasizes the inclusion of stories we live by. Individuals' engagement in identity play in career or business contexts does not necessarily exclude the influence of the stories they live by; the stories that entail the lived experiences of the individuals. Stories evolve and influence each other in time; hence, going beyond situational stories is part of this inclusion. Specifically in organizational studies, just because the modern life has drawn a sharp line between professional and personal lives, it does not mean that stories from both domains are segregated. Additionally, at a given time, there is not necessarily one coherent story, but multiple and even competing stories coexist, as referred to different I-positions (I as a professional, I as female, I as ambitious, I as ....) by the dialogical-self concept.

The philosophy behind the argument proposed in this paper can be seen as a quest to attend to local knowledge versus scientific knowledge and search for meaning in the stories we live by. To make this search fruitful, finding thick descriptions is crucial.

From an epistemological point of view, this paper positions itself within constructivism and constructionism discourse, which view identity as a construction. However, the former sees this construction as that of an individual, while the latter appreciates the complexity of the psychological context and sees identity as a socially negotiated construction.

Drawing on the literatures from narrative therapy, constructivist psychotherapy and the dialogical-self concept and bridging those with identity play literature are the novelties of this paper, contributing to theoretical advancement of identity play phenomenon, and observation of temporality and multiplicity. The bridging of these literatures provides an

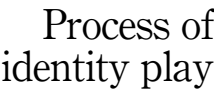


JOCM 33,5

692

opportunity for designing empirical research on identity play by attending to stories we live by, as a parallel stream of research to psychodynamics, but separate from it. Some scholars encourage designing research on psychodynamics for understanding the unconscious aspect of identity construction and the impact of the past (Ashforth et al., 2016; Hoyer and Steyaert, 2015). While we acknowledge the value and insightfulness of such approach, it is worth highlighting that extant literature on identity work and play with a narrative approach has not yet fully integrated the temporality and multiplicity of narratives and more attended to those in situational level at a specific context (Caza et al., 2018). To complement that, by attending to psychodynamics appears as we are dealing with present in the narrative domain, but with the past in psychodynamics, while still we could go farther with in the narrative domain. Although the fusion of these two domains is insightful, the two are from two separate epistemologies. The former is based on local knowledge and subjectivity; the later based on scientific knowledge and objectivity. The emphasis of this paper on the former approach is because narratives form the local knowledge of individuals and are resources immediately available to them. Therefore, investigating narratives has the benefit of providing individuals with an insight into their local knowledge and of promoting self-healing and agency. However, cognitive and psychodynamic analysis, although powerful, are forms of expertise that are applied to individuals.

While the classical view on narratives has focused on coherence and integration, the more contemporary view on narrative identity acknowledges multiplicity, conflict and even contradiction in one's self-narratives (Hermans, 2018). Combining the dialogical-self concept with the discourse of deconstruction provides more means for the explication of identity play, which can be a shift in the I-position of individuals in their ocean of stories, or the de- and reconstruction of those stories.

Based on this proposed conceptual model, empirical research studies can be designed to investigate how individuals facing identity tensions draw on the stories they live by to construe the identity tension and to react to it. Such studies can also take Ashfort et al.'s (2016) conceptual study on identification and identity tension and review study by Winkler (2018) on the role of emotions into account to generate deeper insight into the identity play process.

Identification with stories of influential and significant others such as parents and heroes plays a key role in individuals' development of a sense of self (Ashforth et al., 2016). Hence, research can be designed to investigate the impact of individuals' identifying narratives, such as their narratives of their parents on identity play. That said, caution should be taken that focusing merely on self-defining narratives can prevent us from observing the emergence of identity-constructing narratives from day-to-day conversations and stories.

The conceptual view of this paper, together with the discourse of de- and re-construction of narratives, can contribute to practical domains, such as coaching for individuals and leadership. The pragmatic revelation that we are not merely the actors of our stories, but also the observers, narrators and writers of them is powerful for individuals and leadership to proactively engaging in their identity construction to support the well-being of themselves and their organizations or communities.

\section{Conclusion}

This paper argued that stories we live by are crucial elements of identity play. Highlighting the role of the stories we live by in these processes led to the development of a holistic conceptual model in which identity tension, stories we live by, identity work and play, sensemaking and social validations are all interlinked. Attending to thick descriptions and plurivocality in the stories we live by can help us gain further insight into identity play and the dynamic of shifting from engagement in identity work to play. 
Note

1. Clifford Geertz introduced the term local knowledge in his anthropology studies on culture and search for meaning in indigenous knowledge, rather than in experimental science. According to Geertz, "Believing, with Max Weber, that man is an animal suspended in webs of significance he himself has spun, I take culture to be those webs, and the analysis of it to be therefore not an experimental science in search of law but an interpretive one in search of meaning" Geertz (1973).

\section{References}

Ainsworth, S. and Grant, D. (2012), "Revitalizing scholarship in identity studies", Scandinavian Journal of Management, Vol. 28, pp. 60-62.

Alvesson, M. and Willmott, H. (2002), "Identity regulation as organizational control: producing the appropriate individual”, Journal of Management Studies, Vol. 39, pp. 619-644.

Alvesson, M., Ashcraft, K.L. and Thomas, R. (2008), "Identity matters: reflections on the construction of identity scholarship in organization studies", Organization, Vol. 15, pp. 5-28.

Ashforth, B., Harrison, S. and Corley, K. (2008), "Identification in organizations: an examination of four fundamental questions", Journal of Management, Vol. 34, pp. 325-374.

Ashforth, B.E., Schinoff, B.S. and Rogers, K.M. (2016), “I identify with her,' 'I identify with him': unpacking the dynamics of personal identification IN organizations", Academy of Management Review, Vol. 41, pp. 28-60.

Beech, N. (2008), "On the nature of dialogic identity work", Organization, Vol. 15, pp. 51-74.

Brown, A.D., Stacey, P. and Nandhakumar, J. (2008), "Making sense of sensemaking narratives", Human Relations, Vol. 61, pp. 1035-1062.

Brown, A.D., Gabriel, Y. and Gherardi, S. (2009), "Storytelling and change: an unfolding story", Organization, Vol. 16, pp. 323-333.

Brown, A.D. (2015), "Identities and identity work in organizations", International Journal of Management Reviews, Vol. 17, pp. 20-40.

Cascon-Pereira, R. and Hallier, J. (2012), "Getting that certain feeling: the role of emotions in the meaning, construction and enactment of doctor managers' identities", British Journal of Management, Vol. 23, pp. 130-144.

Caza, B.B., Vough, H. and Puranik, H. (2018), "Identity work in organizations and occupations: definitions, theories, and pathways forward", Journal of Organizational Behavior, Vol. 39, pp. 889-910.

Chiari, G. and Nuzzo, M.. (2010), Constructivist Psychotherapy A Narrative Hermeneutic Approach, Routledge, London and New York.

Conroy, S.A. and O'Leary-Kelly, A.M. (2014), "Letting go and moving ON: work-related identity loss and recovery", Academy of Management Review, Vol. 39, pp. 67-87.

Conway, M. and Pleydell-Pearce, C. (2000), "The construction of autobiographical memories in the selfmemory system”, Psychological Review, Vol. 107, pp. 261-288.

Conway, M., Singer, J. and Tagini, A. (2004), "The self and autobiographical memory: correspondence and coherence", Social Cognition, Vol. 22, pp. 491-529.

Coopey, J., Keegan, O. and Emler, N. (1997), "Managers' innovations as 'sense-making”, British Journal of Management, Vol. 8, pp. 301-315.

Costas, J. and Grey, C. (2014), "The temporality of power and the power of temporality: imaginary future selves in professional service firms", Organization Studies, Vol. 35, pp. 909-937.

Demblon, J. and D'Argembeau, A. (2017), "Contribution of past and future self-defining event networks to personal identity", Memory, Vol. 25, pp. 656-665.

Ericson, M. and Kjellander, B. (2018), "The temporal becoming self-towards a Ricoeurian conceptualization of identity", Scandinavian Journal of Management, Vol. 34, pp. 205-214. 
JOCM 33,5

694

Fachin, F. and Davel, E. (2015), "Reconciling contradictory paths: identity play and work in a career transition", Journal of Organizational Change Management, Vol. 28, pp. 369-392.

Fraher, A.L. and Gabriel, Y. (2014), "Dreaming of flying when grounded: occupational identity and occupational fantasies of furloughed airline pilots", Journal of Management Studies, Vol. 51, pp. 926-951.

Geertz, C. (1973), The Interpretation of Cultures, Basic Books, New York.

Habermas, T. and Bluck, S. (2000), "Getting a life: the emergence of the life story in adolescence", Psychological Bulletin, Vol. 126, pp. 748-769.

Hallford, D.J. and Mellor, D. (2017), "Development and validation of the awareness of narrative identity questionnaire (ANIQ)", Assessment, Vol. 24, pp. 399-413.

Hermans, H.. (2001), "The dialogical self: toward a theory of personal and cultural positioning", Culture and Psychology, Vol. 7, pp. 243-281.

Hermans, H.. (2018), Society in the Self, Oxford University Press, New York.

Hoyer, P. and Steyaert, C. (2015), "Narrative identity construction in times of career change: taking note of unconscious desires", Human Relations, Vol. 68, pp. 1837-1863.

Ibarra, H. and Barbulescu, R. (2010), "Identity as narrative: prevalence, effectiveness, and consequences OF narrative identity work IN macro work role transitions", Academy of Management Review, Vol. 35, pp. 135-154.

Ibarra, H. and Petriglieri, J. (2010), "Identity work and play", Journal of Organizational Change Management, Vol. 23, pp. 10-25.

Koerner, M. (2014), “Courage as identity work: accounts OF workplace courage”, Academy of Management Journal, Vol. 57, pp. 63-93.

Mahoney, M.J. and Granvold, D.K. (2005), "Constructivism and psychotherapy”, World Psychiatry, Vol. 4, p. 4.

McAdams, D.P. and McLean, K.C. (2013), "Narrative identity", Current Directions in Psychological Science, Vol. 22, pp. 233-238.

McAdams, D.P. (1993), The Stories We Live by: Personal Myths and the Making of the Self, W. Morrow, New York, NY.

McLean, K.C., Pasupathi, M. and Pals, J.L. (2007), "Selves creating stories creating selves: a process model of self-development", Personality and Social Psychology Review, Vol. 11, pp. 262-278.

Mink, L.O. (1978), "Narrative form as a cognitive instrument", in The Writing of History, Canary, R.H., (Ed.), University of Wisconsin Press, Madison, pp. 129-149.

Petriglieri, G. and Stein, M. (2012), "The unwanted self: projective identification in leaders' identity work", Organization Studies, Vol. 33, pp. 1217-1235.

Pratt, M., Rockmann, K. and Kaufmann, J. (2006), "Constructing professional identity: the role of work and identity learning cycles in the customization of identity among medical residents", Academy of Management Journal, Vol. 49, pp. 235-262.

Raggatt, P.T.F. (2006), "Multiplicity and conflict in the dialogical self: a life-narrative approach", in Identity and Story: Creating Self in Narrative, McAdams, D.P., Josselson, R. and Lieblich, A., (Eds), American Psychological Association, Washington, DC, pp. 15-35.

Raskin, J.D. (2010), "Theorizing about constructivist therapy", Constructivist Foundations, Vol. 5, pp. 94-96.

Reissner, S.C. (2010), “Change, meaning and identity at the workplace”, Journal of Organizational Change Management, Vol. 23, pp. 287-299.

Rosile, G.A., Boje, D.M., Carlon, D.M., Downs, A. and Saylors, R. (2013), "Storytelling diamond: an antenarrative integration of the six facets of storytelling in organization research design", Organizational Research Methods, Vol. 16, pp. 557-580. 
Shepherd, D.A. and Williams, T.A. (2018), "Hitting rock bottom after job loss: bouncing back to create a new positive work identity", Academy of Management Review, Vol. 43, pp. 28-49.

Singer, J.A. and Bluck, S. (2001), "New perspectives on autobiographical memory: the integration of narrative processing and autobiographical reasoning", Review of General Psychology, Vol. 5, pp. 91-99.

Singer, J. (2004), "Narrative identity and meaning making across the adult lifespan: an introduction", Journal of Personality, Vol. 72, pp. 437-459.

Slay, H. and Smith, D. (2011), "Professional identity construction: using narrative to understand the negotiation of professional and stigmatized cultural identities", Human Relations, Vol. 64, pp. 85-107.

Sveningsson, S. and Alvesson, M. (2003), "Managing managerial identities: organizational fragmentation, discourse and identity struggle", Human Relations, Vol. 56, pp. 1163-1193.

Tracy, S.J. and Trethewey, A. (2005), "Fracturing the real-self <-> fake-self dichotomy: moving toward 'crystallized' organizational discourses and identities", Communication Theory, Vol. 15, pp. 168-195.

Watson, T.J. (2008), "Managing identity: identity work, personal predicaments and structural circumstances", Organization, Vol. 15, pp. 121-143.

White, M. and Epston, D.. (1990), Narrative Means to Therapeutic Ends, W. W. Norton, New York.

White, M. (1997), Narratives of Therapists' Lives, Dulwich Centre Publications.

Winkler, I. (2018), "Identity work and emotions: a review", International Journal of Management Reviews, Vol. 20, pp. 120-133.

\section{Corresponding author}

Babak Ghaempanah can be contacted at: b.ghaempanah@student.vu.nl
Process of identity play 